\title{
E-Government Services Introduction Effects in the Covid-19 Pandemic: 2020-2021 Surveys Results
}

\author{
Vladislav A. Belyi, Andrei V. Chugunov \\ ITMO University, Kronverkskiy prospekt, 49-A, St. Petersburg, 197101, Russia
}

\begin{abstract}
The paper analyzes the development features of e-government services, based on the residents' surveys results. They were conducted in St. Petersburg in 2020 and 2021. The first survey was conducted prior to the introduction of face-to-face restrictions in March 2020. The survey was aimed at getting citizens' opinions on the relevance, trust and attitude towards the «smart city» services. This survey was conducted on a representative sample in multifunctional city centers. Based on survey results, it was decided to conduct an online survey in the summer of 2021 to analyze the services, the levels of their effectiveness as perceived by citizens. This survey was conducted on a representative sample of the population using the Anketolog.ru system. The article presents the results of a surveys comparison. As a study result, the most popular electronic services were identified, as well as stable factors influencing the success of their implementation. It was found that the pandemic has only increased the demand for electronic services in three areas: health, security and transportation. The development dynamic of services was determined, their advantages and disadvantages were named. It is assumed that the economic and temporary benefits from the use of services by citizens will increase. The article also contains guaranteed achievements in the services implementation. The key obstacles are a high level of trust in the authorities, as well as ensuring the safety. It is assumed that the electronic services use level will continue to increase after the coronavirus pandemic. It is concluded that electronic services make it possible to optimize the public administration structure and accelerate the civil society development in Russia.
\end{abstract}

\section{Keywords}

e-government services, e-participation services, electronic government, smart city, COVID19, digital transformation

\section{Introduction}

International structures attach great importance to the adaptation of e-government mechanisms a to the pandemic conditions. According to UN experts, digital technologies have played a key role in maintaining the government work and the society functioning during the coronavirus pandemic [1]. New trends in the digital responses of UN member states to the COVID-19 pandemic are noted by the Division for Public Institutions and Digital Governance (DPIDG) of the UN Department of Economic and Social Affairs (UNDESA) [2]. The Organisation for Economic Co-operation and Development (OECD) in its report «Open Data in Action» during the early stages of the COVID-19 pandemic [3] notes the critical importance of open government data (OGD). This report assesses how OGD has been used to respond to the COVID-19 pandemic in the early stages. The important role of OGD in health communications, providing information to the public about the spread of the pandemic and visualizing the findings was highlighted.

In the European Union, particular attention is being paid to the possibilities of how e-government and e-services can help citizens and businesses during a pandemic [4]. Experts note that solutions in e-government aspects are becoming vitally important, since this also ensures social distancing. International consulting and expert structures also attach great importance to e-government services during the pandemic. The pandemic has made digital technology the backbone of public service delivery, and many large-scale digital innovations have taken place at unprecedented rates, laying the foundation for the future of digital

SSI-2021: Scientific Services \& Internet, September 20-23, 2021, Moscow (online) EMAIL: vladislav@itmo.ru (V.A. Belyi); chugunov@itmo.ru (A.V. Chugunov) ORCID: 0000-0001-6755-2051 (V.A. Belyi); 0000-0001-5911-529X (A.V. Chugunov);

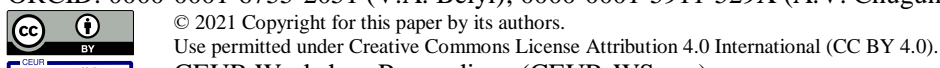
CEUR Workshop Proceedings (CEUR-WS.org) 
government. E-government services key benefits include quick adaptation, efficient service and low cost scaling [5].

Researchers in the e-government services field highlight the important role of the pandemic in electronic services development accelerating, on the one hand [6], and, on the other hand, note the impact the efficiency increasing of Internet technologies and e-government on combating the pandemic consequences [7]. Due to electronic services system, the state can improve the public services efficiency and minimize the spread and COVID-19 transfer to society. Also, the e-government services development can support the economy, contributing to the IT infrastructure development.

Today Russia is not lagging behind the world leaders in the electronic interaction between citizens and authorities. The federal project "Digital Public Administration" operates in the country within the framework of the national program "Digital Economy of the Russian Federation". The project is aimed at ensuring citizens' satisfaction with the provision quality of massive socially significant state and municipal services in electronic form using the Unified portal of state and municipal services. The second direction of the project is the digitalization of providing public services and performing public functions by public authorities. The project key indicator is the provision of massive socially significant services in electronic form at the level of $95 \%$ by 2030.

The system of e-government services is developing in the country in the centralization logic. In Russia, there is a portal "Gosuslugi", which allows solving the citizens basic life situations, and on a unified identification and authentication system basis, access to state information systems is provided. Quarantine measures to prevent the coronavirus epidemic have only accelerated the e-government services development. Several services, mainly in the healthcare sector, appeared precisely during the pandemic. In St. Petersburg, the portal "Health of a Petersburger" was launched. The portal allows you to receive remote consultations using video communication or chat, receive numbers to a doctor, and now sign up for a coronavirus vaccination, which is used by more than half of all those who sign up for vaccinations in the city [8].

At the same time, even after the pandemic, the role of technology is indicated as irreplaceable in achieving the Sustainable Development Goals. UN experts such as Michele Bachelet Jeria is the United Nations High Commissioner for Human Rights and Emilia Sáiz is Secretary General for United Cities and Local Governments (UCLG) assigned the main role in digital transformation to local and regional authorities. According to experts, the authorities should ensure governance processes transparency and improve them to ensure equality. For the most effective implementation of digital technologies and taking into account the opinions and needs of all residents, the Cities for digital rights coalition was created. The organization was created to promote the best practices in the implementation of digital services in order to ensure universal access and a positive impact on urban communities. UN experts note that the digital divide and the pandemic crisis should not contribute to negative trends, infringement of human rights and the principles of accountability in long term services development.

In this regard, questions arise about the further stages of e-government services transformation and development in Russia. The authorities need to understand the immediate needs of the population in order to prioritize the development of portals, to identify positive effects and obstacles as they are implemented.

Since 2018, in St. Petersburg, regular sociological polls have been conducted among government officials and city residents regarding various aspects of the implementation of the Smart City program. During the study in November 2018, the levels of perception of the concept of the «smart city» and the understanding of its constituents by city residents, that is, potential users of services, were determined [9]. The survey, conducted in May 2019, made it possible to assess the trust in the use of information technologies when interacting through electronic portals, forms of electronic applications, as well as trust in electronic voting, portals of electronic services, etc. [10].

In this article, we will analyze the specifics of the development of electronic public services in the context of the coronavirus pandemic based on the results of a survey of residents of St. Petersburg, conducted in March 2020 in the premises of Multifunctional centers for the provision of state and municipal services in order to determine the features of electronic interaction and the level of demand for city network services. as well as a similar 2021 city survey conducted in a fully electronic format. 


\section{Literature review}

The COVID-19 pandemic and the online movement of entire industries and spheres of human life have stimulated interdisciplinary research and are reflected in reviews and reports by global analytical agencies. The Electronic Governance researchers naturally could not ignore this topic, in particular, in September 2021 at the International Conference on Theory and Practice of Electronic Governance the Session «Digital Governance, COVID-19 and post-pandemic challenges» was held. At the session, it was noted that digital technologies have made a significant contribution to solving the problems associated with the pandemic by enabling digital transactions of citizens and enterprises with government agencies, remote work of government officials and remote cooperation between government agencies. COVID-19 has become a powerful driver for the further development of digital governance and public administration transformation. In addition, the use of digital technologies in government is expected to be critical importance for managing the challenges (economic, social, political) in the post-pandemic period [11].

UN experts in the E-Government Survey note that a significant number of people around the world do not yet have access to online services, although states are promoting digital government strategies, especially against the backdrop of the coronavirus pandemic [12]. It is the digital divide that has been identified as the main obstacle to progress in e-governance and e-government. However, virtual health services, ebadges and QR codes, travel tracking apps, online learning and telecommuting have become some of the beneficiaries of the pandemic's restrictions. For example, Estonia has introduced applications for interaction between local authorities and voters, which allow to hold specialized online events. At the same time, the e-government development, as noted in the study, correlates with the economic development. However, this is not a decisive factor in advancing digital government, as political will can dramatically improve performance. In this case, a typical example is the Czech Republic, where the overall positive picture of digitalization is accompanied by an oligopoly of the mobile telephony market, high tariffs and barriers to infrastructure expansion. Insufficient competence of officials may hinder the use of e-government services by citizens. Political collision in a country can undermine the sustainable strategy creation for the public sector digitization [13].

Inter-American Development Bank in the study «Public services and digital government during the pandemic perspectives of citizens, civil servants, and government institutions» [14] notes that a new form of dependence on digital services provides for regions with low Internet connectivity, such as Latin America, serious problems. A survey of citizens, government officials and digital government lead agencies determined that a significant range of services were digitized by governments in a matter of days. Despite an increase from 21 to 39 percent of the Internet using level to gain access to government services amid restrictions, about half of citizens still personally applied to the authorities. Thus, many services were not available to citizens. Experts are coming to the conclusion that it is necessary to improve the access and digital services quality, as well as expand the work of governmental online technologies.

The European Commission's 2021 eGovernment Benchmark Report notes a high level of sustainability and innovative development among European governments. This study is being conducted 18 times and provides an authoritative assessment of the digital transformation of public services in Europe. Due to digital services, relevant templates are created for the further interaction of citizens, authorities and enterprises under conditions of restrictions. However, digital solutions actively implemented due to the pandemic are not universal and have a number of problems. In particular, in the EU, a high level of digitalization is observed when receiving services from the central government, while municipal services are lagging behind. Access to online services for international users is also a major problem - less than half of the services have access to online services [15]. To implement large public investments in the European Union, there is a digitalization program worth more than 670 billion euros. Together, the European community plans to ensure that governments enter the new digital government era.

In the midst of the pandemic, researchers began to pay particular attention to the adoption of e-government services. Similar analytical work began to be carried out in many countries. A study in China found that ease of access to information services and the reliability of COVID-19 data are critical to citizens. When satisfied with these parameters, citizens consider the services useful and are ready to recommend them to their friends [16].

The pandemic is defined by government experts in the Caribbean region as an impetus for the e-governance development [17]. Artificial intelligence and blockchain technologies now play an important role in the e-government services development, bringing the sector to a qualitatively new level. From the simple receipt of information in electronic form, e-government services acquire new functionality. Governments 
are now using e-services infrastructure to provide services such as business licensing, birth and debt registration, driver renewals, tax services, and utility bills. By building a qualitatively new system of interaction with the help of e-government, the transparency and accountability of state authorities is increasing. In this case, experts are talking about improving accessibility and reducing discrimination. Moreover, in the event of various natural disasters, cloud services allow you to save important data, which is especially important for the Caribbean region.

Recent studies in the UK, which are actively deploying applications to track the movement of citizens during a pandemic, emphasize the responsibility of the public sector for digital transformation. In this aspect, researchers note a high level of mistrust in the government, public discontent with possible violations of democratic freedoms and misuse of data collected by applications. Thus, digital transformation can be viewed in the context of socio-political interaction between the state and society. Such innovations provoke public resistance and exacerbate social tensions [18]. However, there is also the opposite opinion among experts that the use of digital technologies in government will be crucial for solving economic, social and political problems in the post-pandemic period [19]. Indeed, without strict restrictions and the use of rapidly scalable electronic services, organizations work could be completely paralyzed. Deloitte law firm experts also demonstrate an optimistic approach to assessing the role of restrictions on the digital services development, arguing that the COVID-19 pandemic has accelerated - in some cases, by years - the advent of truly digital government [20].

Today, the literature points out that the provision of high-quality open data amid a pandemic affects the positive citizens attitude towards government. Analysis of materials posted on social networks shows a direct link between good governance practices and public confidence in governments. The study was conducted on the basis of data analysis about 500 Facebook, Instagram and Twitter followers of the government news agency, analyzed using structural modeling [21]. Thus, states can benefit from communicating with citizens through social networks, increasing not only the level of public awareness, but also trust. In this regard, researchers from Portugal note the importance of electronic disclosure during crises, based on the analysis of the network activity about 300 municipalities during the first wave of the COVID-19 pandemic. The results show that financial autonomy is the main predictor of electronic disclosure, factors varied at different stages of the first wave of the pandemic, and socio-demographic factors came to dominate as explanatory factors as the crisis escalated [22]. A study using data from Google Analytics is devoted to the research of the OGD portal users (Health Data NY) [23]. As a result, the links were found between the higher level of interaction with the site and gender, age group, type of device and consumer interest.

The particular importance of the state media development COVID-19 is emphasized in the context of ensuring information security and citizens cybersecurity. Cybercriminals take advantage of the pandemic for fraud very actively: phishing sites are created, bank data are stolen, users are misled. Government social media accounts are influencing subscriber behavior by raising awareness of cyber threats, according to recent research. Citizens begin to perceive vulnerabilities, react to them competently and make the right decisions [24].

At the end of the review, it should be noted that the research agenda in the direction of Digital Governance under the constraints associated with the COVID-19 pandemic is just emerging, and the results presented in this article make their modest contribution to this process.

\section{Research methodology}

The surveys include questions necessary to determine the parameters of priority, relevance, awareness and citizens confidence in electronic services for interaction between citizens and authorities, receiving state, public and commercial services, solving urban problems and participating in city management.

Since the 2020 survey was conducted during the first wave of coronavirus, due to the introduction of the lockdown in Russia, the survey had to be completed earlier than planned and as a result, answers were received from 564 respondents, resulting in a sampling error of $4.1 \%$, the confidence level is $95 \%$. The sample is representative by sex and age.

The trust level and willingness of citizens to answer questions during the 2020 survey can be assessed as high, since the study was agreed with the authorities, and messages were displayed on information monitors asking visitors to take part in the survey. The respondents could answer by filling out the questionnaire on their own or answer the questions of the interviewers (the interviewers immediately recorded the answers on the tablet through the Anketolog.ru system). 
The current digitalization levels and the results obtained in 2020 on the use of the Internet in general and electronic government services by the population, as well as the coronavirus restrictions, contributed to the online survey through the Anketolog.ru system. After conducting both surveys, using the specified system, a text report and a database in MS Excel format were obtained. Simple distributions and visualization of graphs were obtained using Excel, more complex calculations were carried out using the SPSS program.

\section{Analysis of citizens' opinions on the peculiarities of electronic portals development in the COVID-19 pandemic era}

Based on the results of a survey conducted in 2020, were identified the most priority electronic services for implementation, according to the citizens' opinion. It should be noted that the list of services in the questionnaire reflected plans for the city's digital infrastructure development, since this questionnaire was agreed upon with the city administration. It was found that only $14.18 \%$ of the respondents do not use the Internet to interact with authorities. The largest percentage of those who do not use services was found in the older age groups, and the lowest in the younger ones, which made it possible to conclude that the services popularity was further increasing due to the demographic movement.

During the first survey, in the context of the pandemic, electronic healthcare and medicine services were chosen as the most relevant for development (78\%). The second most relevant were the safe city services that help in emergency situations, ensure interaction with law enforcement agencies (70\%). The third most relevant were electronic services for public transport passengers (63\%). E-participation services became the least relevant (40\%) according to the results. Note that with a decrease in the relevance of services for respondents in 2020, the share of average answers increased, which made it possible to talk about a certain potential for further development due to the responded who were undecided.

This statement was confirmed in a survey conducted in 2021. Despite the fact that the situation with the most and least demanded services has not radically changed, the overall percentage of the services relevance for citizens has grown significantly. So, in 2021, healthcare and medicine services were relevant for $85 \%$ of respondents, safe city services for $79 \%$, and services for public transport passengers for $73 \%$. At the same time, e-participation services have already gained $48 \%$, yet they are still outsiders in the list of services. Attention must be drawn to the fact that in 2021 , only $7 \%$ do not use the Internet to interact with authorities. Detailed results on the relevance of services for citizens in 2020 and 2021 are shown in Table 1.

\section{Table 1}

Demand levels comparison for e-government services (data from ITMO University's E-Governance Center, in percent)

\begin{tabular}{lcc}
\hline \multicolumn{1}{c}{ E-Government Services } & \multicolumn{2}{c}{ Demand level } \\
& In 2020 & In 2021 \\
\hline Healthcare and medicine services & 78 & 85 \\
Safe city services & 70 & 79 \\
Services for public transport passengers & 63 & 77 \\
Services for culture and tourism industry & 56 & 63 \\
Motorist assistance services & 61 & 59 \\
Supplemental educational services & 56 & 58 \\
Services for pet owners & 53 & 57 \\
Services for schoolchildren and their parents & 54 & 54 \\
Services for business & 44 & 49 \\
E-participation services & 40 & 48 \\
\hline
\end{tabular}

In the course of the survey in 2020, respondents were asked to rate the agreement or disagreement degree with some statements (see Table 2). We analyzed the results obtained, dividing them into three groups of values. The ratings "rather agree" and "strongly agree" will be considered as a positive, "rather disagree" and "strongly disagree" - as a negative, and grade 3 - as a neutral. 
Table 2

Degree of agreement with statements from the survey in 2020 (data from ITMO University's E-Governance Center, in percent)

\begin{tabular}{|c|c|c|c|c|c|}
\hline \multirow{2}{*}{ Statement } & \multicolumn{5}{|c|}{ Level of agreement* } \\
\hline & 1 & 2 & 3 & 4 & 5 \\
\hline In general, I trust the authorities of St. Petersburg & 18 & 22 & 35 & 16 & 9 \\
\hline $\begin{array}{l}\text { In general, I trust the interaction with the authorities } \\
\text { through the Internet technologies }\end{array}$ & 9 & 18 & 34 & 24 & 15 \\
\hline $\begin{array}{l}\text { I believe that personal reception is still a more reliable } \\
\text { way of interacting with authorities than via Internet ser- } \\
\text { vices }\end{array}$ & 9 & 14 & 32 & 20 & 25 \\
\hline $\begin{array}{l}\text { When interacting with authorities via the Internet, com- } \\
\text { pared with personal reception, I run the risk of not get- } \\
\text { ting the desired result }\end{array}$ & 11 & 18 & 35 & 21 & 15 \\
\hline $\begin{array}{l}\text { When interacting with authorities via the Internet, com- } \\
\text { pared to personal reception, I save my time }\end{array}$ & 11 & 7 & 25 & 24 & 33 \\
\hline $\begin{array}{l}\text { When interacting with authorities via the Internet, com- } \\
\text { pared to personal reception, I save my money }\end{array}$ & 14 & 14 & 31 & 18 & 23 \\
\hline $\begin{array}{l}\text { Due to the internet, my interactions with the authori- } \\
\text { ties have become easier than in person. }\end{array}$ & 13 & 15 & 30 & 26 & 16 \\
\hline $\begin{array}{l}\text { When interacting with authorities via the Internet, com- } \\
\text { pared to personal reception, I put my personal data at } \\
\text { risk }\end{array}$ & 13 & 18 & 34 & 19 & 16 \\
\hline
\end{tabular}

Note: * The level of agreement is recorded from 1 to 5 , where 1 - strongly disagree, 5 - strongly agree

It can be seen that due to the growing restrictions regime, the issues of interaction between the authorities and citizens through Internet technologies have become actual. In this regard, the problems concerning public confidence in the authorities and trust in digital interaction channels with them are especially relevant. According to the survey results, it was found that, in general, only $25 \%$ of the population would trust the authorities. In unfavorable socioeconomic conditions, such figures are quite understandable. Interaction with authorities through Internet technologies is trusted by $39 \%$ of respondents. The share of those who totally disagree with the statement about trust in interacting with the authorities on the Internet turned out to be two times lower than the share of those who rather disagree. Despite the negative pandemic effects, the confidence parameters in the 2021 survey showed some improvement. So, according to the results of the survey in 2021, $26 \%$ of respondents noted their trust in the authorities, $42 \%$ expressed confidence in interacting with the authorities through Internet technologies.

Note that trust in power on the Internet is directly related to the general level of trust in it. It is possible to consider trust in Internet communication with authorities as a special type of trust only until the algorithms for using Internet services become familiar and understandable, and face-to-face interaction is seen as something unusual. However, an important parameter that affects trust and which must be paid attention to by the authorities in the services development is the citizens confidence in the personal data safety. This one can affect the overall trust in Internet interactions. And here there is a high proportion of those who believe that personal data is at risk because of services - in 2020 there were $35 \%$ of them, and in 2021 $36 \%$.

Also, a high level of mistrust in Internet interaction with authorities may be associated with the lack of knowledge in use network technologies. For example, among those who believe that the Internet absolutely does not help to bring personal problems to the authorities and solve them, about $40 \%$ in the surveys 2020 2021 indicated that they do not have sufficient knowledge to use the Internet when interacting with authorities.

According to the results of the survey in 2020, about half of citizens (45\%) believed that personal reception remained more reliable than remote interaction with authorities and 36\% risked not getting the desired result when interacting with authorities via the Internet. The data obtained indicate that the complete cancellation of face-to-face interaction is not yet possible, and there are serious obstacles on the way to all- 
encompassing electronic interaction. The 2021 survey only confirms this thesis, since the reliability of personal reception compared to Internet interaction was noted by $37 \%$, and the percentage of those who are not confident in obtaining the desired result via the Internet has not changed.

As part of the research, data was obtained on how comfortable, convenient and beneficial to use the existing electronic services. Saving time in 2020 with the help of services was noted by $56 \%$ of respondents, and $41 \%$ of respondents are confident that services can save money, in 2021, these parameters improved markedly to $67 \%$ and $55 \%$.

At the same time, it was found that these services are the most financially beneficial for young people. This is logical, since representatives of older age groups often do not have computers and to use the services it is necessary to buy new expensive devices. In $2020,42 \%$ of respondents noted that the procedure for interacting with the help of the Internet has been simplified, by 2021 this figure has become 55\%.

The use of electronic services for interaction with the authorities is influenced by many criteria. Among them, trust in the government in general, trust in Internet interaction, the level of Internet literacy, cyber threats, and others.

Working with these criteria in order to increase the efficiency of "smart city" services implementation should take into account the sociodemographic population characteristics. The prevailing attitude of the population towards Internet resources signals the need to make changes and transform the approach to the development of services. It can be assumed that first of all, there is a need to increase the Internet literacy of older age groups, the introduction of electronic assistants and chats for user interaction, as well as informing the population about the real possibilities of using services to influence the decisions of the authorities.

\section{Interim conclusions and recommendations}

The introduction of lockdowns and quarantine restrictions overshadowed conversations about the direct economic costs associated with the electronic services for interaction between government and society. Public safety is especially important in a pandemic, and citizens themselves call health and safety services development the most urgent. The state, which uses taxpayers' funds in its social programs, should take care of improving the citizens social conditions, the electronic services implementation in the current environment is precisely such an improvement.

It is obvious that in Russia and in the world, the general use of electronic services for interaction between the authorities and society will also grow, even after the restrictions on electronic interaction are lifted. So, Rostelecom, using the Teqviser platform, analyzed the results of the COVID-19 impact on technological trends and concluded that the result of the pandemic was a change in people to digital technology and a decrease in "natural resistance to innovation", which prepares society for digital transformation [25].

A significant proportion of those surveyed said that electronic services can save time and money. We believe that this figure will grow over time, since the respondents who did not highlight the time and monetary benefits of services, mainly in older age categories. However, a decrease in household income and an increase in the cost of technology may negatively affect the benefits of using electronic services. That is why the state in Russia is concerned about providing free access to several state-important sites and services.

Positive assessments of services can be improved due to the high proportion of those who were identified in the group of average responses, and negative assessments of services can be improved as a result of work on the criteria. Further technological process, an increase in the number of Internet users and an increase in the technological literacy will support the services development. We assume that the low level of digital literacy affects the negative attitude towards services, since the services, in general, do not require the special knowledge of users who already feel confident on the Internet. This hypothesis should be confirmed in further research.

The key technological threat to the electronic government services system development is the personal data vulnerability in government interaction. Today, when gaining access to electronic accounts of citizens, fraudsters can commit illegal actions in relation to the citizens property. The state must ensure the safety of citizens' data, otherwise precedents will arise due to which citizens will avoid interacting with the state electronically, which will further exacerbate the problem of trust in the authorities.

During the further research, it will be determined how the e-government services functionality will affect the overall level of trust in government. At this stage, it can be assumed that it is the ability for citizens to influence management decisions with the help of services that will increase the trust in interaction with the 
authorities on the Internet and in the authorities in general. At the same time, this will increase the demand for these services, since the low interest in services, in particular, e-participation services, can be explained by the insufficiently high level of trust in the authorities.

The current service development logic in the format of a high-tech channel is only a modern interaction form; it does not provide citizens fundamentally new opportunities for interaction and management. Nevertheless, the gradual electronic voting services development will push the state towards an obvious decision - the introduction of real interaction mechanisms between the authorities and citizens on management issues, taking into account opinions and realizing the population's socio-political interest. This is necessary to increase confidence in the authorities and further democratic and socio-economic development of Russian society.

Today electronic services create an opportunity for the authorities to restructure the interaction system, to make it open, transparent and more efficient. The system which is built considering the current social environment and taking into account its negative and positive elements, can establish strong trusting ties between the authorities and residents. This is the most important task on the path of civil society development and growth in the well-being of the population.

\section{Acknowledgements}

We express our gratitude to colleagues from E-Governance Center (ITMO University) for preparing and conducting sociological researches on which this article is based.

\section{References}

[1] M. J. Bachelet, M. S. Mohd, E. Saiz, A. L. Boni, Digital rights in the COVID-19 era. URL: https://www.ohchr.org/Documents/Events/COVID-19/Op-Ed_OHCHR_EUROCITIESES_UCLG_UN_Habitat_XT.pdf

[2] Compendium of Digital Government Initiatives in response to the COVID-19 Pandemic.

URL: https://publicadministration.un.org/en/Themes/Digital-Government/Good-Practices-for-Digital-Government/

[3] Open data in action: Initiatives during the initial stage of the COVID-19 pandemic, March 2021. URL: https://www.oecd.org/gov/digital-government/open-data-in-action-initiatives-during-the-initial-stage-of-the-covid-19-pandemic.pdf

[4] COVID-19: How eGovernment and Trust Services can help citizens and businesses, March 2020 URL: https://digital-strategy.ec.europa.eu/en/news/covid-19-how-egovernment-and-trust-servicescan-help-citizens-and-businesses

[5] Accelerated digital government COVID-19 brings the next generation of digitization to government URL: https://www2.deloitte.com/xe/en/insights/industry/public-sector/government-trends/2021/digital-government-transformation-trends-covid-19.html

[6] Syahrul Ibad, Yona Wahyu Lolita, Development and Urgency of Public Services through E-Government in the Middle of Pandemic Covid-19, Journal of Public Administration and Governance 10 (4) (2020) 263-277.

[7] Atta Ullah, Chen Pinglu, Saif Ullah, Hafiz Syed Mohsin Abbas, Saba Khan, The Role of E-Governance in Combating COVID-19 and Promoting Sustainable Development: A Comparative Study of China and Pakistan. Chinese Political Science Review (2021) 86-118. https://doi.org/10.1007/s41111-020-00167-w

[8] For signing up for vaccinations, citizens most often use the portal "Health of St. Petersburg citizens". Telekanal Sankt-Peterburg, 25 May 2021. URL: https://topspb.tv/news/2021/05/25/dlya-zapisi-navakcinaciyu-gorozhane-chashe-vsego-ispolzuyut-portal-zdorove-peterburzhca/

[9] L. Vidiasova, F. Cronemberger, N. Osipova, E. Bershadskaya, Citizens' Understanding of Smart City Development: The Case of St. Petersburg, Russia, Communications in Computer and Information Science 1135 (2020) 41-54.

[10] L. Vidiasova, Y. Kabanov, Online trust and ICTs usage: Findings from St. Petersburg, Russia, in: ACM International Conference Proceeding Series, 2020, pp. 847-850. https://doi.org/10.1145/3428502.3428637

[11] Digital Governance, COVID-19 and post-pandemic challenges (Paper Session 14), in: International Conference on Theory and Practice of Electronic Governance. 
URL: https://www.icegov.org/track/2021-paper-session-14/

[12] COVID-19 pushes more government activities online despite persisting digital divide, in: Department of Economic and Social Affairs. URL: https://www.un.org/es/desa/covid-19-pushes-more-government-activities-online-despite-persisting-digital

[13] M. Wasiuta, The Czech Republic's struggle with e-government during the COVID-19 pandemic, OSW COMMENTARY 2021-09-08. URL: https://www.osw.waw.pl/en/publikacje/osw-commentary/202109-08/czech-republics-struggle-e-government-during-covid-19-pandemic

[14] B. Roseth, A. Reyes, A. K. Yee, Public Services and Digital Government during the Pandemic: Perspectives of Citizens, Civil Servants, and Government Institutions (Inter-American Development Bank. Washington, D.C.) 2021. http://dx.doi.org/10.18235/0003122

[15] COVID-19 has accelerated Europe's progress towards its goal of making all central and local government services available online by 2030. November 15, 2021. URL: https://www.capgemini.com/resources/egovernment-benchmark-2021/?utm_source=pr\&utm_medium=referral\&utm_content=publicsector_none_link_pressrelease_none\&utm_campaign=other_egovernment_benchmark2021

[16] I. Kofi Mensah, S. Adams, J. K. Adjei, D. S. Mwakapesa, Drivers of egovernment adoption amidst COVID-19 pandemic: The Information Adoption Model (IAM) approach, Information Development, 2021, pp. 1-16. https://doi.org/10.1177/02666669211010872

[17] N. Spencer-Henry, COVID-19 Pandemic - Momentum for E-Government and E-Governance. URL: https://www.caricad.net/covid-19-pandemic-momentum-for-e-government-and-e-governance/

[18] T. Polzer, G. Goncharenko, The UK COVID-19 app: The failed co-production of a digital public service, Financial Acc. \& Man. 2021, pp. 1-18. https://doi.org/10.1111/faam.12307

[19] Digital Governance, COVID-19 and post-pandemic challenges (Paper Session 14), in: International Conference on Theory and Practice of Electronic Governance.

URL: https://www.icegov.org/track/2021-paper-session-14/

[20] M. Sullivan, J. Bellman, J. Sawchuk, J. Mariani, Accelerated digital government. COVID-19 brings the next generation of digitization to government. Deloitte Insights, 04 March 2021. URL: https://www2.deloitte.com/xe/en/insights/industry/public-sector/government-trends/2021/digital-government-transformation-trends-covid-19.html

[21] M. Mansoor, Citizens' trust in government as a function of good governance and government agency's provision of quality information on social media during COVID-19, Government Information Quarterly, vol. 38 (4), October 2021, 101597. https://doi.org/10.1016/j.giq.2021.101597

[22] M. Padeiroa, B. Bueno-Larraz, Â. Freitasc, Local governments' use of social media during the COVID19 pandemic: The case of Portugal, Government Information Quarterly, vol. 38 (4), October 2021, 101620. https://doi.org/10.1016/j.giq.2021.101620

[23] G. M. Begany, E. G. Martin, X. Yuan, Open government data portals: Predictors of site engagement among early users of Health Data NY, Government Information Quarterly, vol. 38 (4), October 2021, 101614. https://doi.org/10.1016/j.giq.2021.101614

[24] Zh. Tang, A. S. Miller, Zh. Zhou, M. Warkentin, Does government social media promote users' information security behavior towards COVID-19 scams? Cultivation effects and protective motivations, $\begin{array}{llllll}\text { Government Information Quarterly, vol. } 38 & \text { (2), April 2021, } 101572 .\end{array}$ https://doi.org/10.1016/j.giq.2021.101572l

[25] COVID - The best thing that has happened to technology in the last 10 years [2021]. Teqviser. URL: https://teqviser.ru/blog/covid-luchshee-chto-sluchalos-s-tehnologiyami-za-poslednie-10-let 